\title{
Maternal Fetal Osmolar Homeostasis: Fetal Posterior Pituitary Autonomy
}

\author{
ROSEMARY D. LEAKE, RICHARD E. WEITZMAN, RICHARD M. EFFROS, SHARON R. SIEGEL, \\ AND DELBERT A. FISHER \\ Departments of Pediatrics and Medicine, UCLA-Harbor General Hospital, Torrance, California, USA
}

\begin{abstract}
Summary
After the infusion of a bolus of $225 \mathrm{mEq} \mathrm{NaCl}$ (HS) to maternal ewes, we studied fetal plasma sodium, osmolality, total serum solids, plasma arginine vasopressin (AVP) and plasma renin activity (PRA) responses in 16 chronically catheterized, 112-139 days of gestation fetal lambs.

To examine the degree to which this might have represented transplacental passage of AVP, we infused a large amount of synthetic AVP into the fetal circulation (protocol 3) and detected no change in maternal plasma AVP. The protocol was designed to allow multiple, frequent blood sampling not possible by infusing the synthetic AVP into the maternal circulation.

In order to compare the fetal AVP response elicited by $\mathrm{HS}$ in the maternal ewe and that after direct HS into the newborn lamb and fetus, we calculated stimulus response ratio (SRR) as:
\end{abstract}

$$
\log (A V P)_{1}-\log (A V P)_{2} \text {, divided by } \Delta \text { osmolality. }
$$

The SRR of lamb fetuses after maternal HS was significantly greater $(0.16 \pm 0.02)$ than that after direct fetal HS $(0.04 \pm 0.01)$. In comparison, the newborn lamb has a SRR of $0.02 \pm 0.01$, and the ewe has a SRR of $0.02 \pm 0.01$ after HS. These data suggest that after maternal HS infusion, both a volume and, to a lesser extent, an osmolar stimulus for AVP secretion occurs after an induced water flux from the fetal to maternal compartments. Maternal plasma sodium concentration rose promptly from a base line of $146 \pm 2.2$ (mean \pm SEM) to $157 \pm 2.8 \mathrm{mEq} /$ liter by 1-20 min where it remained throughout the hour observation period. Fetal plasma sodium concentration rose more slowly from base line of $143 \pm 1.8$ to $149 \pm 1.8 \mathrm{mEq} /$ liter by $1 \mathrm{hr}$. When $85 \mathrm{mCi}^{22} \mathrm{Na}$ was additionally infused with the $\mathrm{HS}$, fetal ${ }^{22} \mathrm{Na}$ constituted only $10 \%$ of maternal ${ }^{22} \mathrm{Na}$ counts by the end of $1 \mathrm{hr}$.

During the same period fetal PRA rose from a base line of 12.9 \pm 3.8 to $32.0 \pm 3.6 \mathrm{ng} / \mathrm{ml} / \mathrm{hr}$, while maternal renin remained unchanged. Maternal AVP rose modestly, 11 min after the HS, but promptly returned to base line. There was a rapid and sustained rise by fetal AVP from a base line of $0.7 \mu \mathrm{U} / \mathrm{ml}$ to a peak of 8.2 $\mu \mathrm{U} / \mathrm{ml}$ by $22 \mathrm{~min}$ post $\mathrm{HS}$.

A fetal SRR,

$$
\frac{\log (\mathrm{AVP})_{1}-\log (\mathrm{AVP})_{2}}{\Delta \text { osmolality }}
$$

after maternal HS was greater than that after direct fetal HS or HS to the ewe or newborn lamb. In an additional experiment, using five chronically catheterized fetuses, 10 million $\mu U$ AVP injected in the fetal circulation failed to produce an increase in maternal AVP.

These results demonstrate that: 1) AVP does not cross the placenta; 2) the fetal sheep neurohypophysis is autonomous and responsive to both direct and indirect (maternal) osmolar stimulation; and 3) the relatively slow rate of maternal to fetal sodium transfer, the augmented SRR after maternal HS, and the elevated fetal PRA and AVP concentration suggest that there is a rapid fetal to maternal flow of water after maternal HS and a combined volume and osmolar stimulus to the fetus.

\section{Speculation}

Infusions of hypertonic saline in pregnant ewes resulted in rapid increases of fetal plasma sodium due to transfer of water from fetus to mother. A marked rise in fetal renin activity and AVP was also observed. The increase in AVP exceeded that seen in the mother and that produced by infusing hypertonic saline in the fetus. Fetal secretion of AVP is stimulated by hyperosmolality and volume contraction. Elevated AVP may help the fetal kidney retain water and, thereby, minimize hypotonic urine formation and volume depletion.

Earlier studies in partially exteriorized rabbit fetuses showed that the iv infusion of hypertonic mannitol to the maternal rabbit produces a transfer of water from the fetal to the maternal circulation (2). Using a chronically catheterized fetal sheep preparation, Faber and Green (3) demonstrated a similar transfer of water in response to maternal osmotic stimulation with mannitol. In addition, the fetus has been shown to respond to direct osmotic stimulation with AVP secretion (3). There are no data, however, quantifying endogenous neurohypophyseal hormonal secretion in the fetal lamb in response to an osmotic stimulus to the ewe. The present studies were undertaken to investigate the autonomy of fetal osmolar responsiveness, to characterize fetal plasma AVP and PRA responses to maternal hypertonicity, and to compare these responses to indirect osmolar stimulation with those of adult ewes, newborn lambs, and lamb fetuses given similar direct osmolar stimulation.

\section{MATERIALS AND METHODS}

Jugular vein and carotid artery catheters were inserted under local anesthesia into 16, date-bred, healthy (Columbia-Suffolk) ewes with singleton fetuses of 112-139 days' of gestation. Ketamine was administered to the ewe and a hysterotomy was performed. The fetal neck was exteriorized and a catheter inserted into the fetal jugular vein and advanced to a site of maximal circulation. The fetus was then replaced in the uterus, the fetal catheter was exteriorized to a pouch attached to the flank of the ewe, and the uterus and maternal abdominal wall closed. Catheters were maintained patent with a dilute heparin solution. Ampicillin was given to the ewe for 5 days postoperatively. The animals were maintained in outdoor pens and received feedings of baled alfalfa and water ad lib. Four to ten days were allowed for recovery from surgery. On the day of study, water and food were removed from the cages. A heparinized fetal blood samples was obtained and the study was undertaken only if the fetal $\mathrm{pH}$ exceeded 7.30. In order to minimize blood sampling, the animals were divided into 
three study protocols to determine 1) the fetal AVP and PRA after a bolus of $\mathrm{HS}$ to the maternal ewe, 2) the amount of sodium transfer from the maternal to fetal plasma, and 3 ) the degree of placental permeability to AVP. No animal participated in more than one study. All fetuses survived at least 1 week after the study was performed.

\section{PROTOCOL 1}

In 7 ewes, three base line blood samples were obtained at 3-min intervals from the ewe carotid artery $(4 \mathrm{ml})$ and fetal jugular vein ( $3 \mathrm{ml})$ for plasma sodium, osmolality, total serum solids, and AVP concentrations and PRA. All samples were removed only after a sample of blood equivalent to the $1.5 \mathrm{ml}$ dead space in the catheter had been withdrawn. Hypertonic sodium chloride (HS), $225 \mathrm{mEq}$ of a $23 \%$ solution $(55 \mathrm{ml})$, was infused via the maternal ewe jugular vein catheter over 1-2 min. Beginning $1 \mathrm{~min}$ after the completion of the HS infusion, eight blood samples were obtained from the ewe and fetus at 2-min intervals. Nine blood samples were obtained every $5 \mathrm{~min}$ for an additional $45 \mathrm{~min}$. These times were chosen to permit evaluation of the immediate and prolonged effects of the HS. Each sample was replaced with an equivolemic quantity of isotonic saline. The blood samples were collected in chilled tubes containing $30 \lambda$ of $15 \mathrm{mg} / 100 \mathrm{ml} \mathrm{K}$ EDTA, spun at $2000 \mathrm{rpm}$ in a refrigerated centrifuge, and the plasma separated. One $\mathrm{ml}$ aliquots were extracted with bentonite as described by Skowsky et al. (6) and stored at $-20^{\circ} \mathrm{C}$ until analyzed for AVP concentration. The remaining plasma was stored at $-20^{\circ} \mathrm{C}$ for measurement of plasma sodium, osmolality, total serum solids, and PRA.

\section{PROTOCOL 2}

An identical protocol was followed in three other animals except for the addition of ${ }^{22} \mathrm{Na}(85 \mathrm{mCu})$ to the $225 \mathrm{mEq} \mathrm{NaCl}$ (HS) injected to quantify the sodium transfer from mother to fetus. Four maternal and fetal blood samples $(0.4 \mathrm{ml})$ were obtained for ${ }^{22} \mathrm{Na}$ and plasma sodium every $5 \mathrm{~min}$, then four samples every 10 min, and three samples every $30 \mathrm{~min}$ thereafter.

\section{PROTOCOL 3}

Placental AVP transfer was determined in 5 other animals. Three $(2 \mathrm{ml})$ base line plasma blood samples were obtained every 3 min from the maternal ewe for AVP, and 10,000,000 $\mu \mathrm{U}$ synthetic AVP (Parke-Davis AVP, lot \#X42819) was injected over $1 \mathrm{~min}$ in the fetal jugular vein. Seven blood samples $(2 \mathrm{ml}$ each) were obtained from the maternal ewe every 4 min thereafter for AVP concentration.

Plasma AVP concentrations were measured using double antibody radioimmunoassays (6). PRA was determined by the method of Haber et al. (4). Plasma sodium was measured by flame photometry and total serum solids by refractometer. Plasma osmolality was determined by freezing point depression, corrected for the contribution of anticoagulant to the measured values.

In order to minimize the effect of episodic secretion of AVP (8), average results were collected for the 10-20 min sampling periods and analyzed by paired $t$ test. Previous studies demonstrated that the rise in plasma AVP after an osmotic stimulus is a logarithmic function of the change in plasma osmolality (7). Because AVP responses are $\log$ normally distributed, it is appropriate to perform a log transformation. The stimulus response ratio is a correction for the osmotic stimulus for statistical comparison. In order to compare responses to those described previously after direct saline infusion to the fetus (9), to newborn lambs (5), and to the maternal ewe (7), a stimulus response ratio (SRR) was calculated for Protocol 1 as follows:

$$
\text { Stimulus response ratio(SRR) }=\frac{\log (\mathrm{AVP})_{1}-\log (\mathrm{AVP})_{2}}{\Delta \text { osmolality }}
$$

\section{RESULTS}

Mean fetal age was 124 days of gestation. As shown in Figure 1 , in response to HS injected into the maternal circulation (Protocol 1), maternal plasma sodium concentration rose from a base line of $146 \pm 2.2$ to $157 \pm 2.8 \mathrm{mEq} /$ liter (mean $\pm \mathrm{SEM}, n=7$ ) by 1-20 min post $\mathrm{HS}$ where it remained for the next $40 \mathrm{~min}$. Fetal plasma sodium concentration increased from a base line of 143 \pm 1.8 to $145 \pm 2.1 \mathrm{mEq} /$ liter by $1-20 \mathrm{~min}$, to $147 \pm 2.1$ by $20-40$ $\mathrm{min}$, and to $149 \pm 1.8 \mathrm{mEq} / \mathrm{liter}$ by $40-60 \mathrm{~min}$. One $\mathrm{hr}$ after the HS injection, the maternal and fetal plasma sodium concentrations had not reached equilibrium.

As shown in Figure 2, basal AVP was nearly identical $(0.7 \pm$ $0.1 \mu \mathrm{U} / \mathrm{ml} v$ s. $0.7 \pm 0.2 \mu \mathrm{U} / \mathrm{ml})$ in maternal and fetal plasma. Maternal plasma AVP $\left(\mathrm{P}_{\mathrm{AvP}}\right)$ peaked at $2.6 \pm 1.8 \mu \mathrm{U} / \mathrm{ml}(P<$ $0.05), 11 \mathrm{~min}$ after maternal HS infusion, returning to base line by 20 min postinjection where it remained throughout the study. Fetal $P_{A v P}$ began to rise from base line at $7 \mathrm{~min}$, peaking at 8.2 $\pm 2.4 \mu \mathrm{U} / \mathrm{ml}, 25 \mathrm{~min}$ after maternal injection. There was a significant sustained elevation of fetal $P_{A V P}$ over 20-40 min. $P_{A V P}$ then fell toward base line over the remainder of the 1 -hr observation period.

As shown in Figure 3, there was no significant change in maternal base line PRA during the study period. Fetal PRA rose

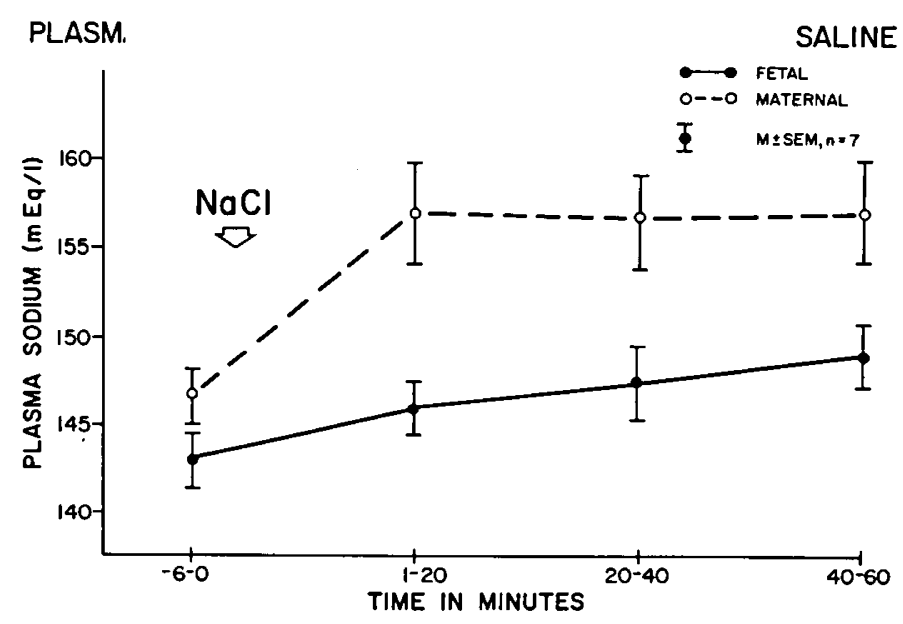

Fig. 1. Plasma sodium concentration after HS to 7 ewes. Time in min represents collation of data over various study periods.

\section{PLAS}

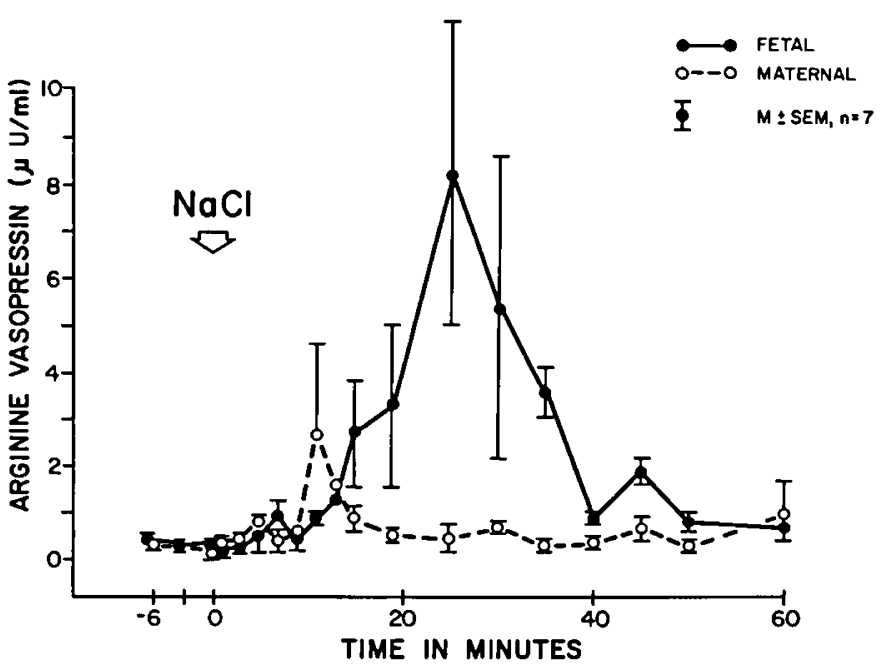

Fig. 2. Plasma AVP in matched samples of fetal and maternal plasma at various time periods before and after $\mathrm{HS}$ to the ewe. 
from a base line of $12.9 \pm 3.8 \mathrm{ng} / \mathrm{ml} / \mathrm{hr}$ to $32.0 \pm 3.6 \mathrm{ng} / \mathrm{ml} / \mathrm{hr}$ $(P<0.05)$ 40-60 min after injection.

There was a significant decrease in maternal total serum solids from a basal concentration of $6.3 \pm 0.2 \mathrm{~g} / \mathrm{dl}$, to $5.6 \pm 0.2 \mathrm{~g} / \mathrm{dl}, \mathrm{l}-$ 20 min after maternal HS $(P<0.05)$. Maternal total serum solids increased slightly thereafter, approaching basal levels by $40-60$ min. Fetal plasma total serum solids were not significantly changed during the study period.

As shown in Figure 4, when tracer quantities of ${ }^{22} \mathrm{Na}$ were injected into the maternal circulation of 3 ewes along with the HS (Protocol 2), ${ }^{22} \mathrm{Na}$ in the fetal circulations rose over the first $10-$ min period postinjection to $5 \%$ that of maternal counts and from $10-120$ minutes to $10 \%$ of maternal counts.

After the infusion of $10,000,000 \mu \mathrm{U}$ synthetic AVP into the fetal circulation in five animals (Protocol 3), maternal AVP did not change from base line concentration (range $=0.4-1.0 \mu \mathrm{U} / \mathrm{ml}$ ).

The fetal SRR, $\left(\log [\mathrm{AVP}]_{1}-\log [\mathrm{AVP}]_{2}\right.$ divided by $\Delta$ osmolality), after $\mathrm{HS}$ to the ewe, to newborn lambs, and after direct fetal injection are shown in Table 1. The SRR of lambs to HS $(\mathrm{SRR}=0.02)$ was nearly identical to that measured in adult ewes

\section{PLA}

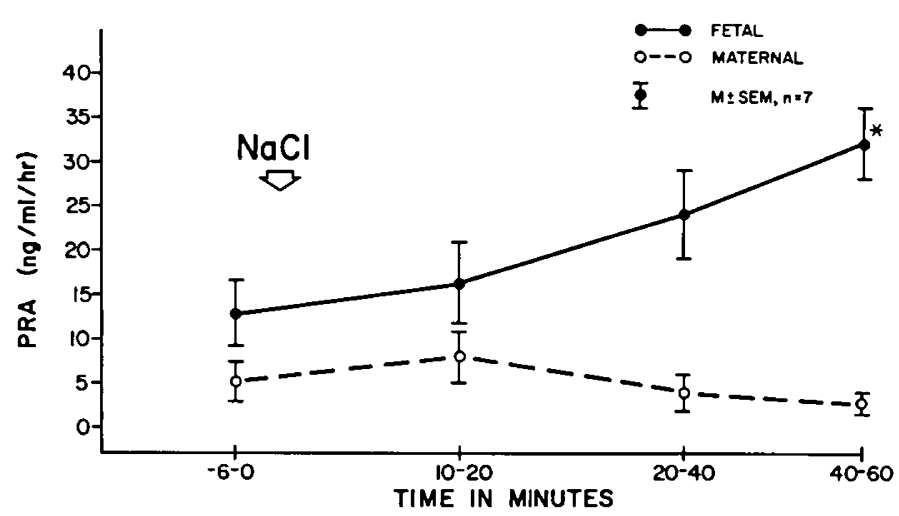

Fig. 3. PRA in matched samples of fetal and maternal plasma at various time periods before and after $\mathrm{HS}$ to the ewe.

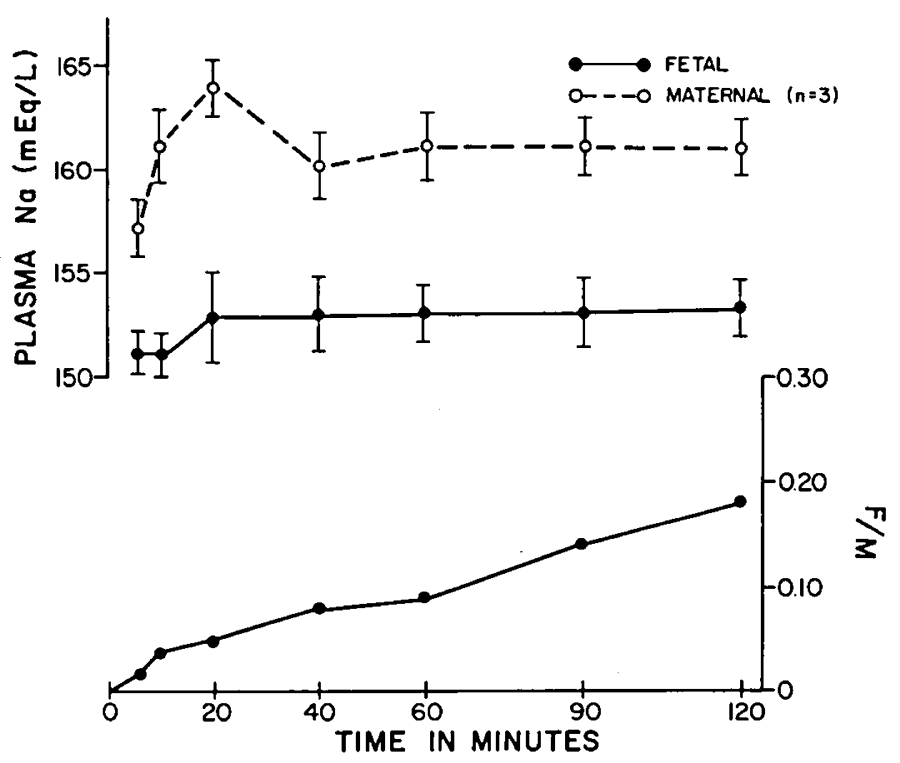

Fig. 4. Placental ${ }^{22} \mathrm{Na}$ transfer after the injection of ${ }^{22} \mathrm{Na}$ and $\mathrm{HS}$ in three maternal ewes. The upper panel represents sodium concentrations (mean \pm SEM) in the fetal $\left(\mathrm{O}_{-} \mathrm{O}\right)$ and maternal $\left(\mathrm{O}_{---\mathrm{O}}\right)$ plasma. The lower panel shows the ratio $(\mathrm{F} / \mathrm{M})$ of ${ }^{22} \mathrm{Na}$ activity in the fetal blood to the ${ }^{22} \mathrm{Na}$ activity in the maternal blood.
Table 1. SRR after $H S$ in various animals

$$
\mathrm{SRR}=\frac{\log [\mathrm{AVP}]_{1}-\log [\mathrm{AVP}]_{2}}{\Delta \text { osmolality }}
$$

\begin{tabular}{lc}
\hline \multicolumn{1}{c}{ Animal } & \multicolumn{1}{c}{ SRR $^{\prime}$} \\
\hline Ewe & $0.02 \pm 0.01$ \\
Newborn lamb & $0.02 \pm 0.01$ \\
Fetus & $0.04 \pm 0.01$ \\
Fetus after maternal injection & $0.16 \pm 0.02^{2}$ \\
\hline
\end{tabular}

\footnotetext{
${ }^{1}$ Mean \pm SEM.

${ }^{2} P<0.01$.
}

(7). The fetal SRR after maternal HS (SRR $=0.16$ ) is greater than that in any of the other animals including direct fetal HS injection $(S R R=0.04)(9)$. The augmented fetal response after maternal HS represents a combined volume and osmolar stimulus to the fetus after the rapid transfer of water from the fetal to maternal compartments.

\section{DISCUSSION}

There is increasing recognition that the fetus plays an important part in the regulation of its own water and electrolyte metabolism. Little is known, however, concerning the fetal response to an osmotic alteration in the mother. Bruns et al. (2) infused hypertonic mannitol to maternal rabbits, and demonstrated a $2.4 \%$ decrease in fetal water content and total blood volume, associated with an increase in fetal plasma sodium concentration and a decrease in maternal sodium concentration. Faber and Green (3) administered mannitol $(1.8 \mathrm{~m})$ and $0.4 \mathrm{NaCl}$ over $1 \mathrm{hr}$ in $1-2$ liters of water to the chronically catheterized maternal ewe. Fetal plasma osmolality, sodium, potassium, and hemoglobin concentrations rose without detectable mannitol transfer into the fetal circulation and without a rise in maternal sodium concentration. These studies suggest a fetal to maternal induced water flux.

The results of the present study show the fetal AVP and PRA responses to maternal hyperosmolality. Using chronically catheterized sheep fetuses in the third trimester, we induced water shifts from the fetal to the maternal compartments by means of a HS infusion to the maternal ewe. A relatively small bolus of HS was chosen so that there would be no effect on the maternal-fetal circulation during the study. In response to HS, maternal sodium concentration rose immediately to a concentration $12 \mathrm{mEq} / \mathrm{liter}$ above the basal level. Plasma sodium plateaued at this level for the entire study period. The ewes responded to the osmolar stimulation with a rise in AVP from $0.7 \pm 0.1 \mu \mathrm{U} / \mathrm{ml}$ to $2.6 \pm 1.8$ $\mu \mathrm{U} / \mathrm{ml}(P<0.05)$. In addition, maternal PRA decreased slightly over the 1-hr observation period, reflecting a shift into the maternal extracellular fluid space of intracellular and fetal water.

After maternal HS, there was a dysequilibrium between fetal and maternal sodium, fetal levels remaining at base line until 11$15 \mathrm{~min}$ after maternal HS. Thereafter, there was a gradual linear increase in plasma sodium concentration in the fetus. This finding may have represented an induced water shift from the fetal to maternal compartment or a transfer of maternal sodium to the fetal circulation. The latter possibility is less likely in view of the demonstration that the addition of tracer quantities of ${ }^{22} \mathrm{Na}$ to the maternal HS (protocol 2) resulted in a fetal/maternal ratio of ${ }^{22} \mathrm{Na}$ of 0.05 at $20 \mathrm{~min}$ and 0.1 at $60 \mathrm{~min}$ postinjection. This adds further evidence that the increase in fetal sodium represents fetal dehydration. Additional supporting data includes the significant rise in fetal PRA after maternal HS.

Plasma AVP values were identical in mother and fetus at base line $(0.7 \mu \mathrm{U} / \mathrm{ml})$, but fetal concentrations peaked $22 \mathrm{~min}$ after the maternal injection at a markedly elevated level $(8.2 \pm 2.4 \mu \mathrm{U} / \mathrm{ml})$. This initial rise in fetal AVP reflects a response to both an increase in osmolality and a small decrease in volume. Thus, the fetal endocrine response after maternal HS is autonomous and appropriate even at the beginning of the third trimester. The subsequent 
decrease in AVP despite a continued increase in fetal plasma sodium (40-60 min) may represent a discontinuation of the volume stimulus or exhaustion of the readily releasible pool in response to sustained stimulation.

\section{REFERENCES AND NOTES}

I. Battaglia, F., Prystowsky, H., Smisson, C., Hellegers, A., and Bruns, P.: The effect of the administration of fluids intravenously to mothers upon the concentrations of water and electrolytes in plasma of human fetuses. Pediatrics, 25: 2 (1960).

2. Bruns, P. D., Linder, R. O., Drose, V. E., and Battaglia, F.: The placental transfer of water from fetus to mother following the intravenous infusion of hypertonic mannitol to the maternal rabbit. Am. J. Obstet. Gynecol., 86: 160 (1963).

3. Faber, J. J., and Green, T. J.: Foetal placental blood flow in the lamb. J. Physiol., 223: 375 (1972)

4. Haber, E., Koerner, T., Page, L. B., Kliman, B., and Purnode, A.: Application of a radioimmunoassay for angiotensin $I$ in normal human subjects. J. Clin. Endocrinol. Metab., 29: 1349 (1969).

5. Leake, R. D., Weitzman, R. E., Weinberg, J. A., and Fisher, D. A.: Control of

Copyright (C 1979 International Pediatric Research Foundation, Inc. $0031-3998 / 79 / 1307-0841 \$ 02.00 / 0$ vasopressin secretion in the lamb. Pediatr. Res., 11: 428 (1977).

6. Skowsky, W. R., Rosenbloom, A. A., and Fisher, D. A.: Radioimmunoassay of arginine vasopressin in serum: development and application. J. Clin. Endocrinol. Metab., 38: 278 (1974)

7. Weitzman, R. E., and Fisher, D. A.: Log-linear relationship between plasma arginine vasopressin and plasma osmolality. Am. J. Physiol., 233: E238 (1977).

8. Weitzman, R. E., Fisher, D. A., DiStefano, J. J., and Bennett, C. M.: Episodic secretion of arginine vasopressin. Am. J. Physiol., 233: E231 (1977).

9. Weitzman, R. E., Fisher, D. A., Robillard, J., Erenberg, A., Kennedy, R., and Smith, F.: Arginine vasopressin response to an osmotic stimulus in the fetal sheep. Pediatr. Res., 12: 35 (1978).

10. Presented, in part, at the Society for Pediatric Research Meeting, San Francisco, CA, April, 1977.

11. This research was supported by grant HD-06335 from The National Institute of Child Health and Human Development. The National Institutes of Health, Bethesda, MD (USA).

12. Requests for reprints should be addressed to: Rosemary D. Leake, M. D., Department of Pediatrics, Harbor General Hospital, 1000 West Carson Street, Torrance, CA 90509 (USA).

13. Received for publication February 22, 1978

14. Accepted for publication July 19, 1978. 